\title{
Phytophthora palmivora: A New Pathogen of Olive Trees in Morocco
}

\author{
Mohamed Chliyeh', Amina Ouazzani Touhami', Abdelkarim Filali-Maltouf², Cherkaoui El \\ Modafar ${ }^{3}$, Abdelmajid Moukhli ${ }^{4}$, Ahmed Oukabli ${ }^{5}$, Rachid Benkirane ${ }^{1}$, and Allal Douira ${ }^{1 *}$ \\ 'Laboratoire de Botanique et de Protection des Plantes, UFR de Mycologie, Département de Biologie, Fac- \\ ulté des Sciences BP. 133, Université Ibn Tofail, Kénitra, Maroc; ${ }^{2}$ Laboratoire de Microbiologie et Biologie \\ Moléculaire, Faculté des Sciences, Université Mohammed V Agdal, Av Ibn Batouta, BP 1014 Rabat, Maroc; \\ ${ }^{3}$ Laboratoire de Biotechnologie, Valorisation et Protection des Agroressources, Faculté des Sciences et Tech- \\ niques Guéliz, B.P. 618, 40000 Marrakech, Maroc; ${ }^{4}$ UR, Amélioration génétique des plantes, Institut national \\ de la Recherche agronomique F- 40000 Marrakech, Maroc; ${ }^{5}$ Institut national de la Recherche agronomique, \\ Amélioration des plantes et Conservation des ressources phytogénétiques CRRA, BP 578, Meknès, Maroc.
}

Received: January 17, 2013 / Accepted: March 11, 2013

\begin{abstract}
In spring of 2012, olive-trees with crown dieback, root rot and defoliation were observed in two years old olive tree in commercial plantations of tree nurseries in Sidi Taibi and in twenty to fifty years old field trees in Souk El Arbaa olive crops in Northwest of Morocco (Gharb area). The objective of this study was to isolate the responsible pathogen of the observed symptoms to the olive trees, to demonstrate its pathogenicity and fulfill the Koch's postulate. Phytophthora palmivora was consistently isolated from roots $(56 \%)$ and stems $(73.6 \%)$ of the young olive trees and $85 \%$ from stems of field trees. Koch's postulate was completed using two isolates of Phytophthora palmivora on 2-year old plants of Dahbia and Haouzia varieties grafted onto wild olive-trees. The affected branches percentages (Pab\%) of the inoculated olive plants with the isolate 1 were higher $(81.8 \%$ for Dahbia and $68 \%$ for Haouzia) than those what were inoculated with the isolate 2 (43\% for Dahbia and $32 \%$ for Haouzia). The reisolation percentages $(\mathrm{Pr} \%)$ of isolate $1(84 \%)$ and isolate $2(76 \%)$ in the roots of Dahbia variety were higher than isolate $1(48 \%)$ and isolate $2(55 \%)$ in roots of Haouzia variety. The reisolation percentage of isolate 1 in the stem of Dahbia (64\%) was higher than that in the stem of Haouzia $(41.33 \%)$. No significant difference was observed between the Reisolation percentages of isolate $\mathbf{2}$ in stem of Dahbia olive plants $(38 \%)$ and in stem of Haouzia olive plants $(33 \%)$.
\end{abstract}

* Corresponding author: douiraallal@hotmail.com
The pathogenicity of P. palmivora was demonstrated in the olive plants and this was the first report of this pathogen in Moroccan olive trees.

Key words: Olive tree crown dieback, root rot, defoliation, Phytophthora palmivora, Koch's postulate, pathogenicity.

\section{Introduction}

Olive-tree (Olea europaea L.) is one of the most ancient domesticated fruit trees and the most extensively cultivated fruit crop in the world (Fabbri, 2009). In Morocco, the olive plantation is estimated at about 650000 ha accounting for $50 \%$ of the national surface dedicated to arboreal crops (Ministry of Agricultural and Marine Fischeries, 2009).

This cultivar is susceptible to major fungal diseases particularly to leaf-spot disease caused by Spilocaea oleagina, the most widespread fungal disease of olive tree in the world (Anton \& Laborda, 1989), Verticillium dahliae responsible to defoliation and wilting of olive trees and death of young trees (Vossen et al., 2008), and Fusarium solani that provokes the root rots to the olive trees (Perez et al., 2011). In 2012, a survey of nurseries in Sidi Taibi and in olive trees field in Souk El Arbaa, allowed us 

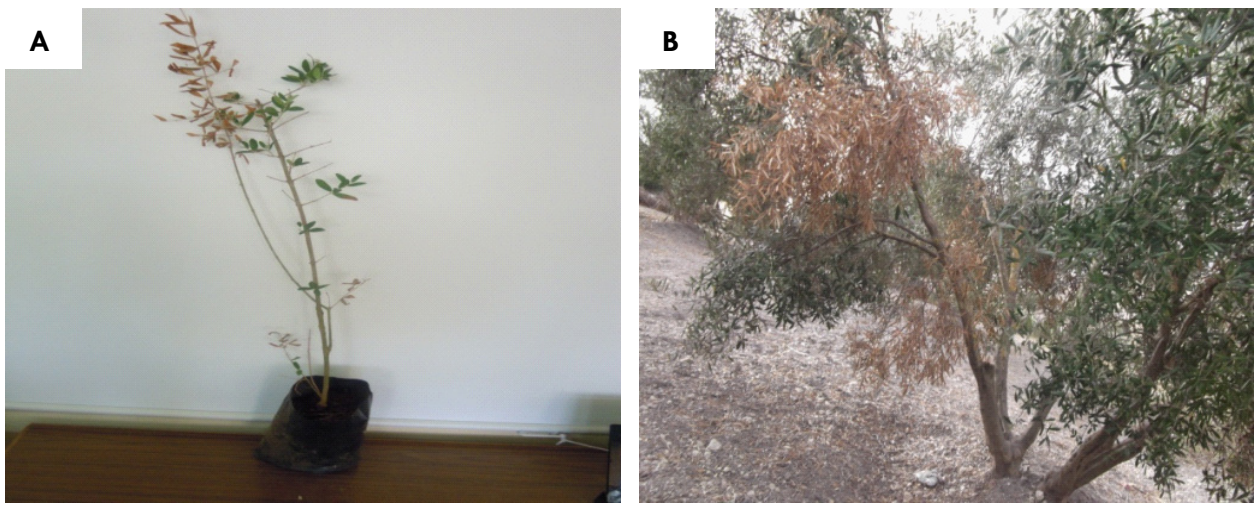

Figure 1. Leaf chlorosis, defoliation, wilting and twig in some olive trees collected from Sidi Taibi nurseries (A) and Souk El Arbaa fields in the Gharb area (B).

to remark the presence of leaf chlorosis, defoliation, wilting and twig dieback in some olive plants (Figure 1).

The objective of this study was to isolate the responsible pathogen of the observed symptoms to the olive trees, to demonstrate its pathogenicity and to fulfill the Koch's postulate.

\section{Material and Methods}

\section{Pathogen Isolation}

One hundred stem segments and one hundred root segments of olive trees were taken from commercial plantations of tree nurseries in Sidi Taibi and one hundred stem segments from the olive crops in Souk El Arbaa, washed with water, disinfected with alcohol for five minutes, put on sterile distilled water and then dried with sterile filter paper. Then they were put on PSA agar plates (Potato Sucrose Agar: $200 \mathrm{~g}$ potato, $15 \mathrm{~g}$ sucrose, 20 g Agar-Agar, and $1,000 \mathrm{ml}$ distilled water) and incubated on darkness at $28^{\circ} \mathrm{C}$. The developing colonies were then observed for species determination.

Isolation percentage ( $\mathrm{Pi} \%$ ) was obtained by applying the following formula:

$$
\mathrm{Pi}=\mathrm{N}_{\mathrm{sX}} / \mathrm{N}_{\mathrm{T}} \times 100
$$

$\mathrm{N}_{\text {sX }}$ : Number of segments containing the fungal species $X$.

$\mathrm{N}_{\mathrm{T}}$ : Total number of used segments.

Nine $\mathrm{mm}$ diameter agar plugs from these plates were placed in a $5 \mathrm{~cm}$ diameter Petri dishes and soil extract was added to just cover the plugs. Soil extract was prepared by mixing 10 $\mathrm{g}$ of soil and 1 litre of distilled water. After $24 \mathrm{~h}$ at $20^{\circ} \mathrm{C}$, the mixture was filtered and Petri dishes were incubated in darkness at $15^{\circ} \mathrm{C}$. After each $24 \mathrm{~h}$ incubation, the soil extract was removed and replaced with fresh extract previously stored at 4 $\circ C$. Sporangial production and development, occurring between 12 and $120 \mathrm{~h}$, was assessed by direct observation using an optical microscope. Mature sporangia were removed and placed on glass microscope slides and stained with blue cotton.

\section{Inoculum Production}

Zoospores of $P$. palmivora were produced by growing cultures on oatmeal agar at $28^{\circ} \mathrm{C}$ in the dark for 14-21 days. The mycelium was transferred to a sterile Petri dish, covered with sterile distilled water (SDW) and incubated overnight at $28^{\circ} \mathrm{C}$, under lights. The mycelia plates were chilled for $5 \mathrm{~min}$ at $-20^{\circ} \mathrm{C}$ to induce zoospores release. The concentration of the inoculum was adjusted at 105 zoospores/ml by SDW.

\section{Inoculation Test}

The Koch's postulate was verified by inoculating twelve olive plants of Haouzia and Dahbia varieties (six plants per variety) with two isolates of Phytophthora palmivora (Isolate 1: isolated from the nursery olive trees and Isolate 2 : isolated from the Souk El Arbaa olive trees field). Three plants from each variety were none inoculated and used as a control.

Plants were inoculated according to the method described by Olbricht et al. (2006). The roots of investigated plants were washed under running water to discard soil remnants, trimmed to $2 / 3$ of their length, and subsequently dipped in the prepared inoculum during 6 hours. The olive trees plants were potted into universal soil substrate, watered with the remaining fungal suspension (about $20 \mathrm{ml}$ per plant), and cultivated in a greenhouse. For control plants, sterile water was used instead of fungal suspension.

\section{Pathogen Reisolation}

At the end of each test, twenty five roots and stems segments were taken from inoculated plants and controls, washed with water, disinfected with alcohol for five minutes, put on SDW and then dried with sterile filter paper. After, they were plated on PSA and incubated on obscurity at $28^{\circ} \mathrm{C}$

The symptoms were evaluated after five weeks of inoculation, the number of new formed branches $\left(N_{n b}\right)$ and the number of affected branches $\left(N_{a b}\right)$ were estimated on the inoculated olive plants and the percentages of the affected branches $\left(\mathrm{P}_{\mathrm{ab}} \%\right)$ were calculated using the formula: 


$$
P_{a b}(\%)=N_{a b} / N_{n b} \times 100
$$

Reisolation percentage ( $\operatorname{Pr} \%$ ) was obtained by applying the following formula:

$$
\operatorname{Pr}=\mathrm{N}_{\mathrm{sPp}} / \mathrm{N}_{\mathrm{T}} \times 100
$$

NSPp: Number of segments containing Phytophthora palmivora. NT: Total number of segments used in the reisolation.

Analysis of the variance and of the mean comparisons using the LSD test ( $p=5 \%$ ) were performed using the software STATISTICA program. Statistical analyses focused on the results of five plants, for the affected branches and five repetitions for the reisolation percentage of the inoculated and non inoculated plants.

\section{Results and Discussion}

Fungi morphological characterization showed that all isolates produced papillate sporangia on the soil extract medium (Figure $2 \mathrm{a})$, which were ellipsoid to ovoid with a length of $18.31 \mu \mathrm{m}$ and a larger of $13 \mu \mathrm{m}$. Some isolates produced subglobose, non-papillate sporangia (Figure $2 \mathrm{~b}$ ) and abundant chlamydospores (Figure 2c), sexual forms were absents (heterothallic species).

The pathogen causing disease on the olive trees was identified as Phytophthora palmivora on the basis of morphological and cultural characters especially on sexual and asexual reproduction forms (Ho et al., 1992. Cacciola et al., 2000. Lucero et al.,
2006. Gallegly and Hong, 2008).

On the PSA plates, some colonies appeared four days later on the segments of stems and roots of the diseased olive trees (Figure 3). The microscopic observations leaded us to identify simultaneously the isolated species as Phytophthora palmivora $(\mathrm{Pi}=73.6 \%)$ and Alternaria alternata $(\mathrm{Pi}=26.4 \%)$ in the stem fragments of the young olive trees from the nurseries. In the field olive-trees, the isolated species from the stem fragments were $P$. palmivora $(85 \%)$ and $A$. alternata $(15 \%)$. The root segments of the young olive trees showed the presence of $P$. palmivora and Fusarium solani with 56 and $44 \%$ frequencies respectively.

After five weeks of inoculation, all the plants showed defoliation (Figure 4-A2, A3, B2 and B3), wilting, degradation and reduction of root system (Figure 4- C2, C3, D2 and D4) necrosis and dropping of the new branches and vascular browning primarily of the xylem tissue (Figure 4).

Table 1 showed that Dahbia olive trees inoculated with isolate 1 formed on average of 12.8 branches (Figure 5A) significantly fewer at $p=5 \%$ than those inoculated with isolate 2 (21.6). Haouzia olive plants inoculated with isolate 1 and isolate 2 formed the same number of new branches (17). The obtained results were statistically significant at the $5 \%$ level for the isolate 2 of Phytophthora palmivora, this isolate affected more new branches in Haouzia (5.6) and Dahbia (9) varieties than isolate 1 in the same varieties ( 11.8 and 10.8, respectively) (Figure 5B).

The affected branches Percentages of the inoculated olive plants with the isolate 1 were significantly higher $181.8 \%$ for Dahbia and $68 \%$ for Haouzia) than those of plants varieties inoculated with isolate 2 (43\% for Dahbia and 32\% for Haouzia) (Table 1).
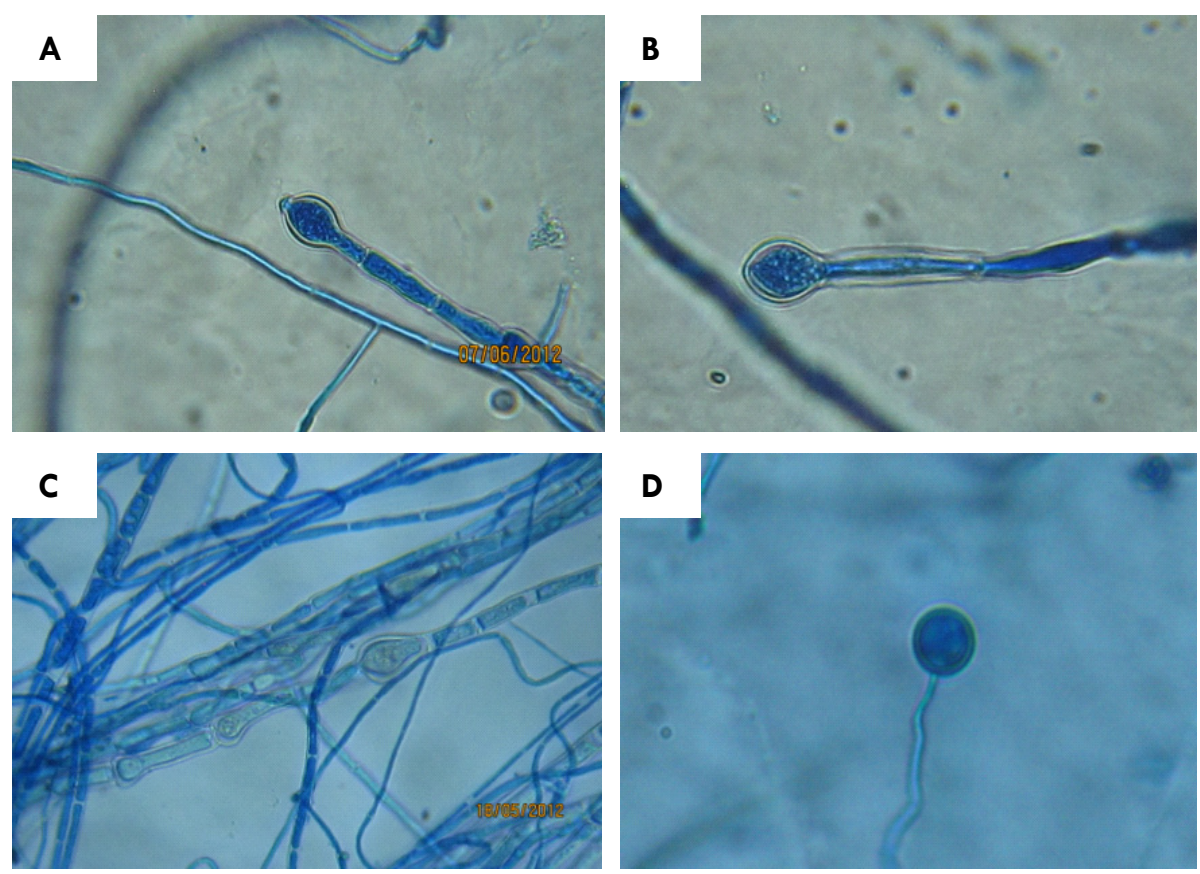

Figure 2. Morphological characterization of Phytophthora palmivora. Papillate sporangia (A), Non semi-papillate sporangia (B), Hyphal swellings (C), Terminal chlamydospore (D) on cotton blue $(\times 400)$. 
Table 1. Percentage of the affected branches relative to the new formed branches on the inoculated olive trees of Dahbia and Haouzia varieties with Phytophthora palmivora after five weeks of inoculation.

\begin{tabular}{ccccc}
\hline Variety & $\begin{array}{c}\text { Phytophthora } \\
\text { palmivora }\end{array}$ & $\begin{array}{c}\text { New formed } \\
\text { branches }\end{array}$ & $\begin{array}{c}\text { Affected } \\
\text { branches }\end{array}$ & $\begin{array}{c}\text { Percentage of the } \\
\text { affected branches (\%) }\end{array}$ \\
\hline Dahbia & Isolate 1 & $12.8 \mathrm{c}$ & $10.8 \mathrm{ab}$ & 81.8 \\
& Isolate 2 & 21.6 & $9 \mathrm{~b}$ & $43 \mathrm{c}$ \\
\multirow{2}{*}{ Haouzia } & Isolate 1 & $17 \mathrm{c}$ & 11.8 & $68 \mathrm{~b}$ \\
& Isolate 2 & $17 \mathrm{c}$ & $5.6 \mathrm{c}$ & $32 \mathrm{~d}$ \\
\hline
\end{tabular}

The results of the same column followed by different letters differ significantly at $5 \%$.
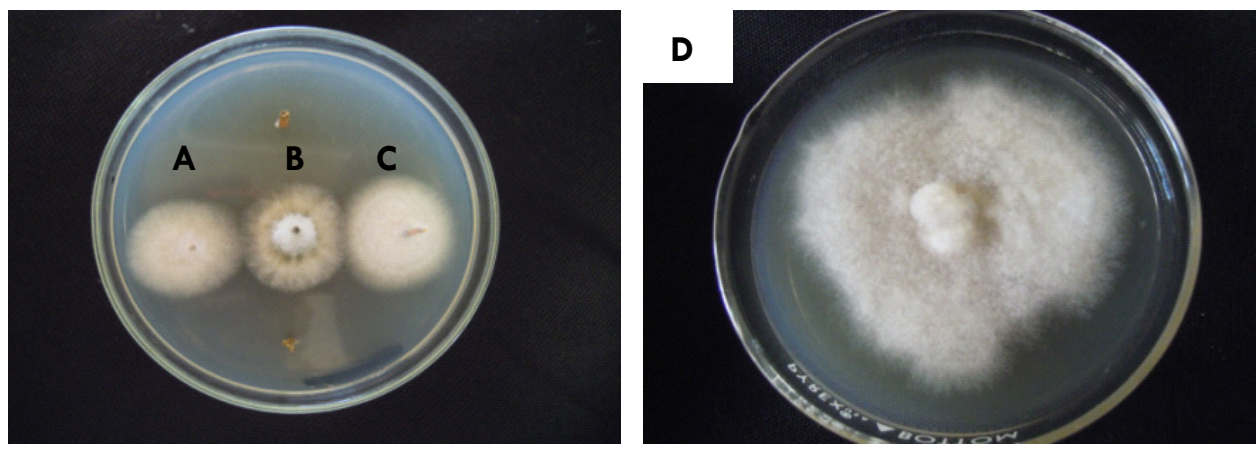

Figure 3. Phytophthora palmivora (A, C), Alternaria alternata (B) isolated from the olives stem segments on PSA agar and Phytophthora palmivora in the age of 12 days on the PSA agar plate (D).
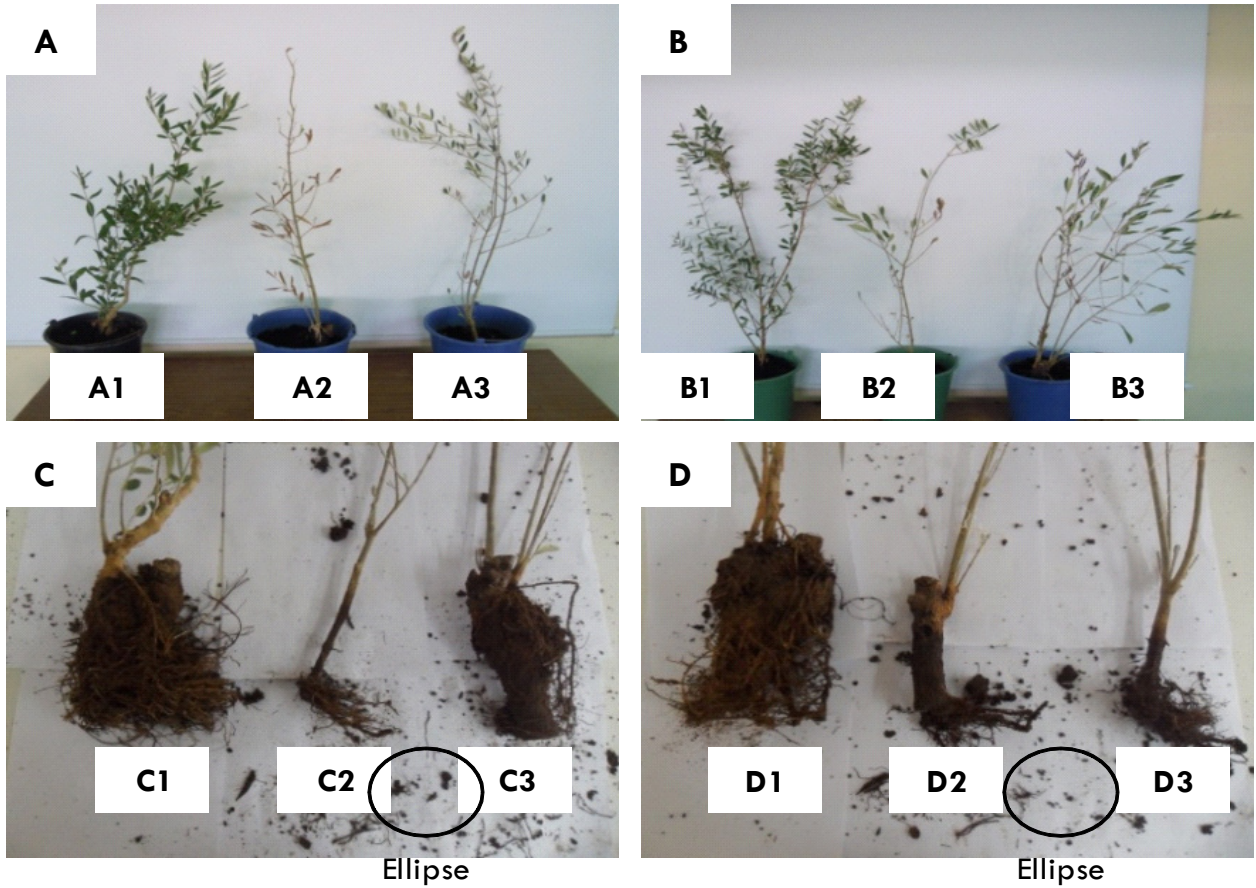

Figure 4. Symptoms on different organs of olive trees after inoculation with two isolates of Phytophthora palmivora: Olive trees of Dahbia variety(A), Non inoculated plant (A1), Inoculated plant with isolate 1 (A2), Inoculated plant with isolate 2 (A3), Olive trees of Haouzia variety (B), Non inoculated plant (B1), Inoculated plant with isolate 1 (B2), Inoculated plant with isolate 2 (B3), Olive trees root system of Dahbia variety $(C)$, non inoculated plant $(C 1)$, Inoculated plant with isolate 1 (C2), Inoculated plant with isolate 2 (C3), Olive trees root system of Haouzia variety (D), non inoculated plant (D1), Inoculated plant with isolate 1 (D2), Inoculated plant with isolate 2 (D3), roots degradation due to the inoculation with the isolates of Phytophthora palmivora (Ellipse). 
Table 2. Reisolation percentage of Phytophthora palmivora from roots and stems of the inoculated olive trees of Haouzia and Dahbia varieties after five weeks of inoculation.

\begin{tabular}{llll}
\hline Variety & Phytophthora & \multicolumn{2}{l}{ Reisolation percentage (\%) } \\
\cline { 3 - 4 } & palmivora & Root & Stem \\
\hline Dahbia & Isolate 1 & $84 \mathrm{a}$ & $64 \mathrm{a}$ \\
& Isolate 2 & $76 \mathrm{~b}$ & $38 \mathrm{bc}$ \\
\multirow{2}{*}{ Haouzia } & Isolate 1 & $48 \mathrm{c}$ & $41,33 \mathrm{~b}$ \\
& Isolate 2 & $55 \mathrm{~d}$ & $33 \mathrm{c}$ \\
\hline
\end{tabular}

The results of the same column followed by different letters differ significantly at $5 \%$.
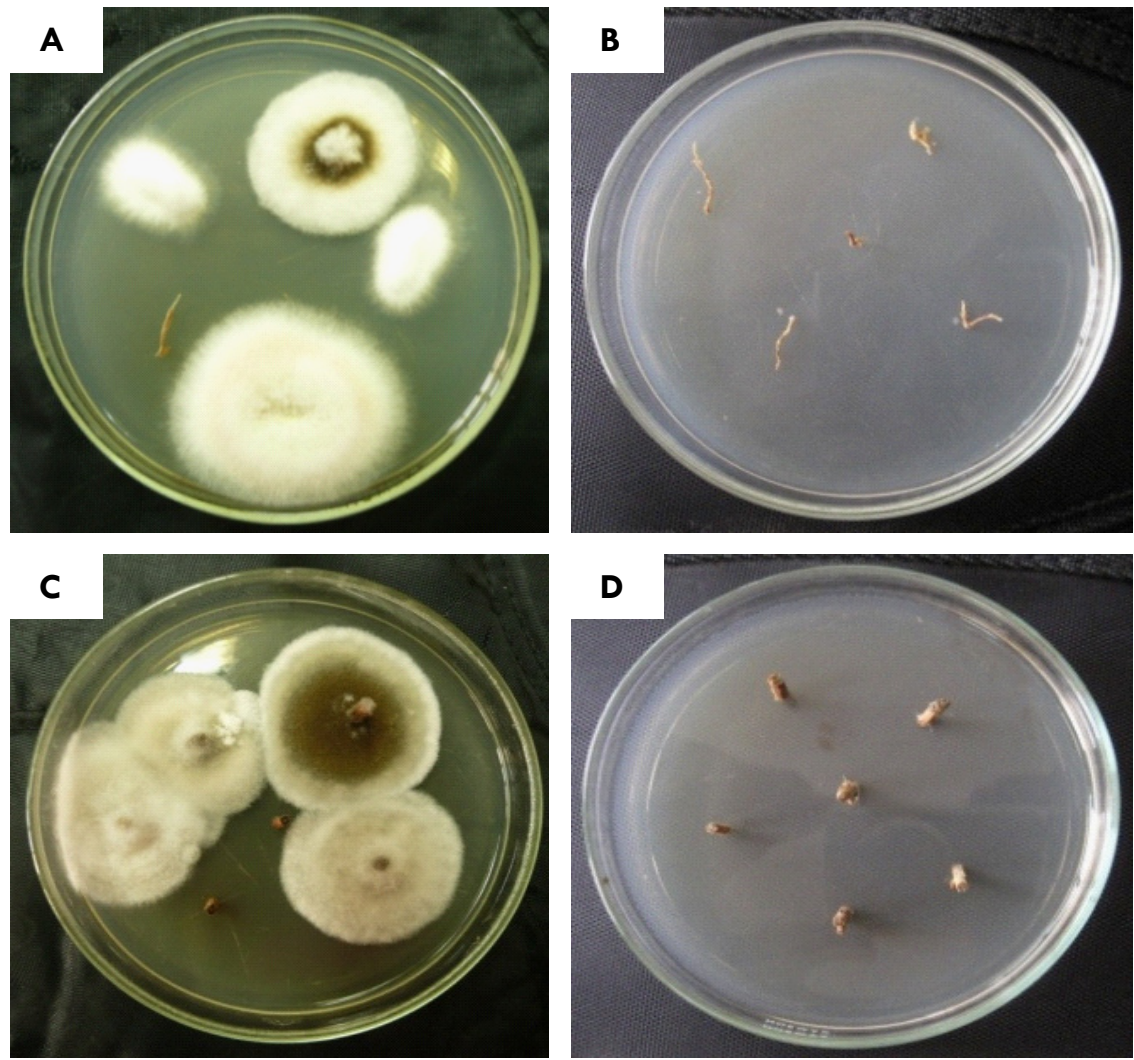

Figure 6. Reisolation of Phytophthora palmivora from the inoculated olive tree on PSA agar. Phytophthora palmivora reisolated from root segments (A), the control root segments (B), Phytophthora palmivora reisolated from stem segments (C), the control stem segments (D).

The two isolates of $P$. palmivora were reisolated from the root and stem with A. alternata (Figure 6). As shown in Table 2, the reisolation percentage of isolate $1(84 \%)$ was significantly higher at $5 \%$ than that of isolate $2(76 \%)$ in the root of Dahbia trees. The reisolation percentage of isolate $1(48 \%)$ was lower than that of isolate $2(55 \%)$ in the root of Haouzia trees.

In the stems of Dahbia, isolate 1 was higherly reisolated (64\%) than isolate $2(38 \%)$. The reisolation percentage of isolate 1 $(41.33 \%)$ was higher than isolate $2(33 \%)$ in the stem of Haouzia.

The Koch's postulate was verified by inoculating olive trees of Haouzia and Dahbia varieties with two isolates of Phytophthora palmivora isolated from the nursery olive tree and the olive trees
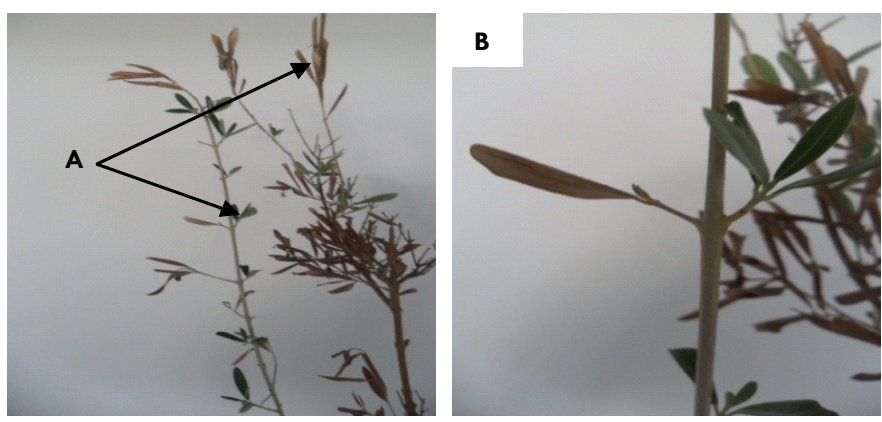

Figure 5. Inoculated olive plant with Phytophthora palmivora. Affected branch (A), New formed branch (B). 
isolates produced papillate sporangia. Olive plants could have been contaminated by $P$. palmivora from other host species as suggested by these authors. P. palmivora infects more than 200 species of ornamental, shade and hedge plants, mostly from tropical areas. In Argentina, for instance, P. palmivora was first recorded in Citrus spp in 1937. The pathogen may have been introduced through rooted olive plants of Mediterranean varieties currently used in Argentina (Lucero et al., 2006).

As regards the ability of Phytophthora palmivora to reduce and to degrade the olive tree roots, we could find the same symptoms that Lucero announced in 2006.

Lo Giudice et al. (2010) outlined that leaf chlorosis, defoliation, rot of fine roots, twig dieback and wilt were observed in 4-year-old olive trees cv. Tonda lblea in drip-irrigated orchard in eastern Sicily. Trees declined slowly or collapsed suddenly with withered leaves still attached. Incidence of affected trees was $10 \%$. A fungus identified as $V$. dahliae Kleb. was isolated from the xylem of main roots and basal stem. An oomycete was isolated and identified from roots and basal trunk bark. Both pathogens were recovered from symptomatic trees with means frequencies of positive isolations per tree of 80 and $30 \%$ for $V$. dahliae and $P$. palmivora, respectively.

The pathogenicity of $P$. palmivora was demonstrated in the olive plants. This was the first report of this pathogen in Moroccan olive trees. In the long-term, it may constitute a real danger to this culture in the nurseries as in the fields. So, due to the severe symptoms and the increasing incidence recorded; $P$. palmivora should be considered a potential threat to olive cultivation in Morocco.

\section{Acknowledgments}

This study was conducted under the project 'Rhizolive: Selection and use of soil rhizospheric microorganisms to optimize the arbuscular mycorrhization of olive tree in Morocco's soils' funded by the Hassan II Academy of Sciences and Technology. We thank the Academy for its financial support.

\section{References}

Anton FA and E Laborda (1989) Estudio de la susceptibilidad/resistancia de variedades del olivo (Olea europaea L.) al patogeno Cycloconium oleaginum (Cast.) (Spilocaea oleaginae Hugh.). Bol. San. Veg. Plagas, 4: 385-403.

Cacciola SO, Agosteo GE, and A Pane (2000) First Report of Phytophthora palmivora as a Pathogen of Olive in Italy. Plant disease 84 (10): 1153.

Fabbri A, Lambaradi M, and YO Tokatli (2009) Olive breeding in breeding plantation tree crops : Tropical species. Spinger New York pp. 423-465.

Ho HH (1992) Keys to the species of Phytophthora in Taiwan. Plant Pathol. Bull. 1: 104-109.

Lo Giudice V, Raudino F, Magnano Di San Lio R, Cacciola SO, Faedda $R$, and A Pane (2010) First report of a decline and wilt of young olive trees caused by simultaneous infections of Verticillium dahliae and Phytophthora palmivora in Sicily. Plant Disease 94 (11): 1372.

Lucero G, Vettraino AM, Pizzuolo P, Di Stefano C, and A Vannini (2006) First report of Phytophthora palmivora on olive trees in Argentina. New Disease Reports 14: 32.

Ministry of Agriculture and marine Fischeries (2009) Plan vert du Maroc: de la stratégie à l'action du Maroc.

Gallegly ME and CX Hong (2008) Phytophthora: Identifying species by morphology and DNA fingerprints. American Phytopathology Society Press 158pp.

Olbricht K, Ulrich D, and B Dathe (2006) Cross-breeding with accessions of Fragaria chiloensis resulting in selections with outstanding disease resistance and fruit quality characteristics. Acta Hortic. 708: 507-509.

Perez $A B$, Farinon $O M$, and MF Berretta (2011) First report of Fusarium solani causing root rot of olive in southeastern Argentina. Plant Disease $95(11): 1476$.

Sanchez Hernandez ME, Ruiz Davila A, Perez De Algaba A, Blanco Lopez MA, and A Trapero Casas (1998) Occurrence and etiology of death of young olive trees in southern Spain. European Journal of Plant Pathology 104 (4): 347-357.

Vossen P, Gubler D, and MA Blanco (2008) Verticillium Wilt of Olive. Newsletter of Olive Oil production and Evaluation. Univ. of California Cooperative Extension. Vol. 3 (4): 1-4. 